\title{
Fractal characteristics of nanopores in lacustrine shales of the Triassic Yanchang Formation, Ordos Basin, NW China
}

https://doi.org/10.1515/geo-2019-0016

Received Dec 17, 2018; accepted Jan 16, 2019

\begin{abstract}
To further understand fractal characteristics of nanopores in lacustrine shales, core samples from Chang7 and Chang-9 members of the Triassic Yanchang Formation, southern Ordos Basin were investigated. Total organic carbon content, vitrinite reflectance, X-ray diffraction, field emission-scanning electron microscopy and low pressure $\mathrm{N}_{2}$ physisorption (LPNP) experiments were performed. The Frenkel-Halsey-Hill (FHH) method was applied to characterize the fractal dimensions using LPNP isotherms. Two fractal dimensions $\left(\mathrm{D}_{1}\right.$ and $\left.\mathrm{D}_{2}\right)$ were determined at relative pressures of 0-0.45 and 0.45-1, respectively. The Chang-7 shales have a $D_{1}$ and $D_{2}$ range of 2.172.36 and 2.46-2.63, while the Chang-9 shales have $\mathrm{D}_{1}$ values of 2.23-2.40 and $\mathrm{D}_{2}$ values of 2.46-2.64. Fractal dimensions of the selected lacustrine shales are affected by shale mineral compositions and pore structure parameters. Positive correlations of $\mathrm{D}_{1}$ and $\mathrm{D}_{2}$ with clay minerals and quartz contents, and negative correlations of $\mathrm{D}_{1}$ and $\mathrm{D}_{2}$ with TOC contents were presented in the present study. Observations of few organic matter pores and abundant inorganic pores hosted in the Yanchang shales may contribute to these correlations. In addition, comparisons of matrix composition, nanopore fractal characteristics between the Chang-7 shales and the Chang-9 shales suggest that the latter may have more irregular and heterogeneous pore structure.
\end{abstract}

Keywords: Lacustrine shales, Fractal dimensions, Pore structure, Chang-7 shales, Chang-9 shales, Yanchang Formation, Ordos Basin

\footnotetext{
*Corresponding Author: Ling Tang: State Key Laboratory of Petroleum Resources and Prospecting, China University of Petroleum, Beijing, 102249, China; Unconventional Natural Gas Research Institute, China University of Petroleum, Beijing, 102249, China; Email: tanglingcup@126.com; Tel.: +86-188-1096-7810

Zhuo Li, Zhenxue Jiang, Zhikai Liang, Hailong Yu, Youdong Yang, Lei Xiao: State Key Laboratory of Petroleum Resources and Prospecting, China University of Petroleum, Beijing, 102249, China;
}

\section{Introduction}

Shale gas refers to thermogenic or biogenic gas stored as free gas, absorbed gas and/or dissolved gas within organic shales [1-3]. Shales commonly have complex porous networks with different pore types and wide pore size distribution [4-6]. Investigation of pore structure is significant to understand methane storage and flow mechanisms in gas shales. Pore structure can be effectively characterized by microscopic observation, radiation detection and fluid intrusion techniques [7-11]. In addition, fractal theory provides a novel method for quantitatively describing the heterogeneity of porous rocks [12, 13]. Based on low pressure $\mathrm{N}_{2}$ physisorption (LPNP) isotherms, fractal dimensions of pores in coals and shales can be characterized by the Frenkel-Halsey-Hill (FHH) model [10, 14-17]. The fractal dimension $\mathrm{D}$ varies from 2 to 3 . The lowest value 2 corresponds to a perfectly smooth surface or homogenous pore structure, while the upper value 3 refers to an irregular surface or heterogeneous pore structure $[8,14]$. Recently, fractal characteristics of pores in marine shales around the world were extensively studied [10, 17-21], however, few investigations about the nanopore fractal dimensions of lacustrine shale were reported.

The black shales and mudstones in the Chang-7 and Chang-9 members of the Triassic Yanchang formation deposited in deep lacustrine sedimentary facies are the primary targets for lacustrine shale gas exploration [22, 23]. To understand the pore structure and fractal characteristics of lacustrine shales, a series of experiments were conducted including Total organic matter contents (TOC), vitrinite reflectance $\left(\mathrm{R}_{o}\right)$, X-ray diffraction $(\mathrm{XRD})$ and experiments of field emission-scanning electron microscopy (FESEM) and LPNP.

The objectives of the present work are to: (1) investigate the fractal dimensions of pores in lacustrine shales Unconventional Natural Gas Research Institute, China University of
Petroleum, Beijing, 102249, China 


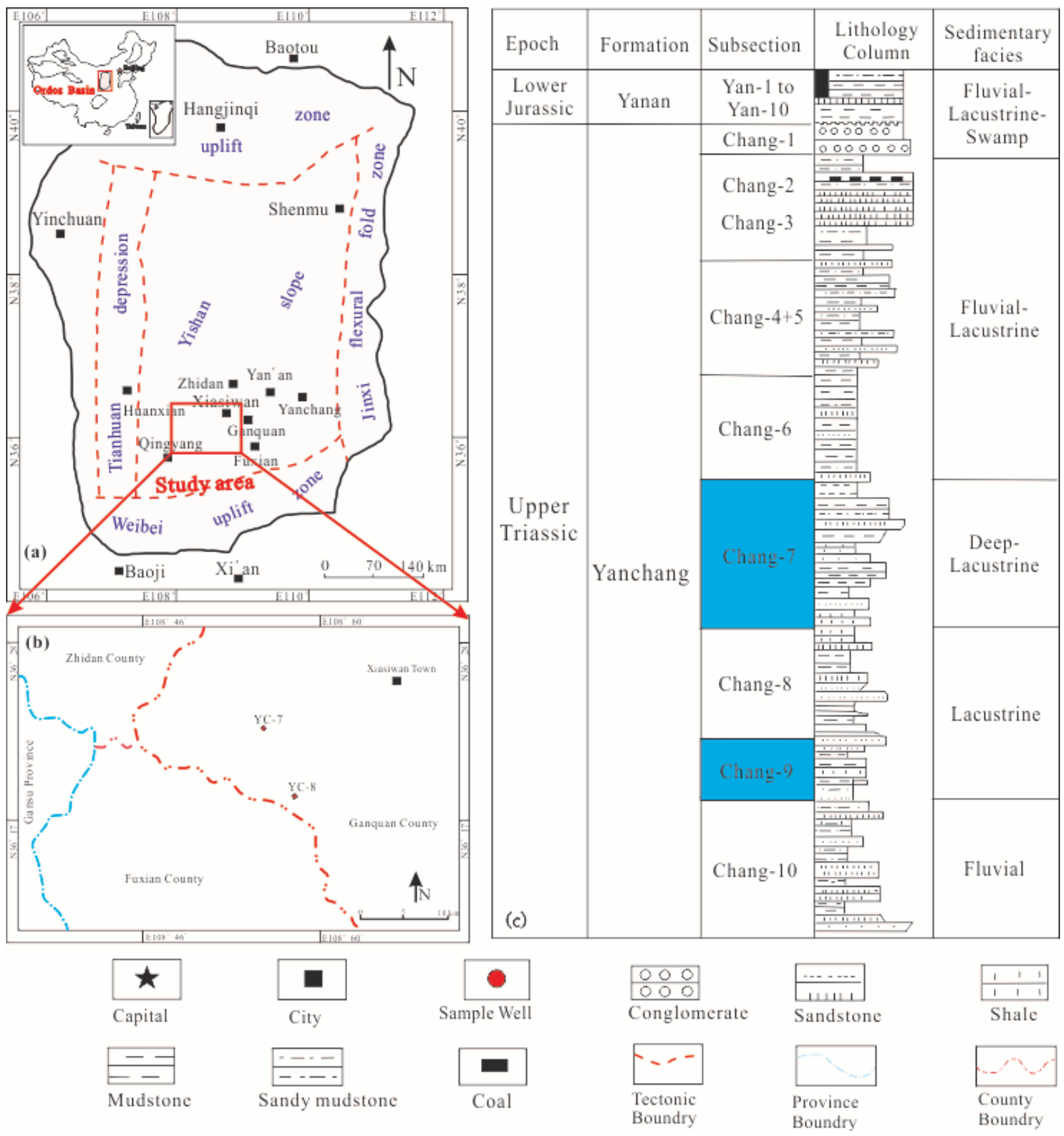

Figure 1: (a) Location of the study area, which is marked with red box; (b) Location of the sampling wells; (c) stratigraphy column showing petrology and depositional facies of Yanchang Formation (after [26]).

using FHH method based on LPNP data; (2) compare the fractal dimensions of pores in the Chang-7 shale and the Chang-9 shale; (3) discuss the controls of matrix compositions and pore structure parameters on the fractal dimensions of the lacustrine Yanchang shales.

\section{Samples and Methods}

In total, 25 lacustrine shale samples were collected from wells YC-7 and YC-8 in the study region, which is in southern Ordos Basin (Figure 1). These core samples were from a depth range of $1343.77-1613.35 \mathrm{~m}$. Shales in the Chang-7 and Chang-9 members in the Yanchang Formation are deposited in a semi-deep lacustrine environment, with rela- 


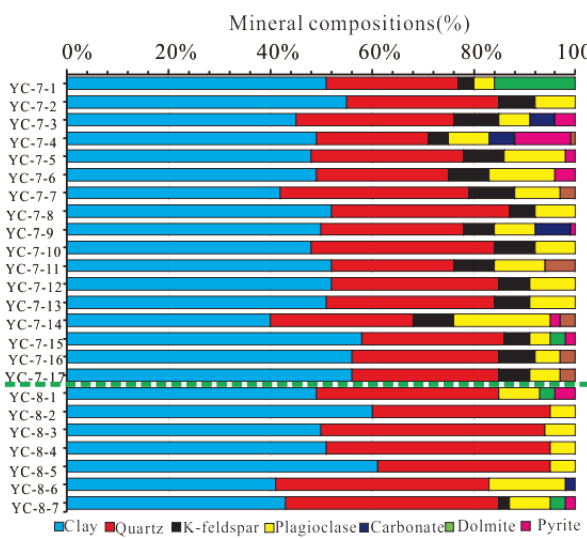

(a)

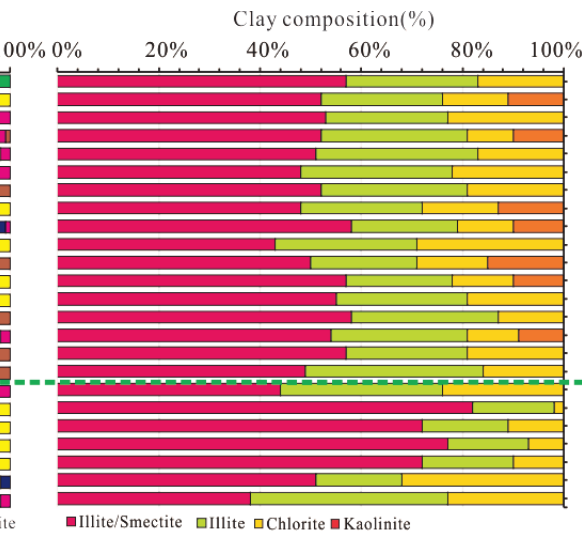

(b)

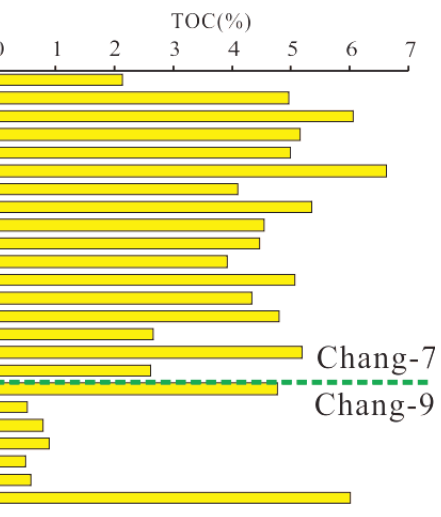

(c)

Figure 2: Geochemical and mineralogical compositions of the selected lacustrine shales in Ordos Basin. (a)-(b) Histogram of bulk minerals and clay minerals components. (c) TOC content and Ro values.

tively large thickness (Figure 1c). The organic matter types are primarily sapropelic [22, 23].

Total organic matter contents (TOC), vitrinite reflectance $\left(\mathrm{R}_{o}\right)$, X-ray diffraction (XRD), field emissionscanning electron microscopy (FE-SEM) and LPNP experiments were conducted following the Chinese national standard for shale gas evaluation (GB/T 31483-2015). Briefly, TOC contents were tested on a LECO CS230 carbon/sulfur analyzer using 100 mesh samples after carbonates removed. $\mathrm{R}_{o}$ values were measured on an MPV-SP micro-photometer. Bulk mineral compositions were analyzed using a D8 Discover XRD apparatus. FE-SEM observations were conducted using a Zeiss SUPRA 55 Sapphire SEM equipped with secondary electron (SE), backscattered electron (BSE) detectors. LPNP experiments were conducted with a Quantachrome SI surface area analyzer with temperature at $77 \mathrm{~K}$ and relative pressure from 0.001 to 0.998. The BET (Brunauer-Emmett-Teller) and BJH (Barrette-Joyner-Halenda) models were applied to calculate pore structure parameters. The FHH model, for calculating fractal dimensions, can be described as [14]:

$$
\ln V=(D-3) \ln \left(\ln \frac{P_{0}}{P}\right)+C
$$

Where, $P$ is the equilibrium pressure, $\mathrm{MPa} ; P_{o}$ is the gas saturation pressure, $\mathrm{MPa} ; V$ is the volume corresponding to the equilibrium pressure $P, \mathrm{~cm}^{3} / \mathrm{g} ; D$ is the fractal dimension, and $C$ is a constant.

\section{Results}

\subsection{Mineral compositions}

Bulk mineral compositions of the lacustrine shale samples are listed in Table 1. The samples are clay rich, with average clay mineral contents of $50.23 \mathrm{wt} \%$ (40 wt $\%-58 \mathrm{wt} \%$ ) in Chang-7 shales and $54.2 \mathrm{wt} \%$ (43 wt\%-58 wt\%) in Chang9 shales, respectively (Table 1, Figure 2a). In addition, a mixed-layer of illite/smectite (I/S) contributes the greatest proportion in clay contents, with a mean value of 60.59 wt $\%$ (45 wt $\%-79$ wt $\%$ ) in Chang-7 shales and $65.38 \mathrm{wt} \%$ (44 wt $\%-88$ wt $\%$ ) in Chang-9 shales (Table 1, Figure $2 b$ ). The quartz content varies from $22 \mathrm{wt} \%$ to $37 \mathrm{wt} \%$ with an average of $29.05 \mathrm{wt} \%$ in Chang- 7 shales, and varies from $34 \mathrm{wt} \%$ to $44 \mathrm{wt} \%$ with an average of $39.12 \mathrm{wt} \%$ in Chang- 9 shales. Trace abundance of carbonates, dolomite and pyrite were identified in both members (Table 1).

\subsection{Geochemistry}

The Chang-7 shales are richer in organic matter than the Chang-9 shales. Average TOC contents of Chang-7 shales and Chang-9 shales are $2.61 \mathrm{wt} \%(0.49 \mathrm{wt} \%-6.86 \mathrm{wt} \%)$ and $4.52 \mathrm{wt} \%$ (2.14 wt\%-6.65 wt \%). The $\mathrm{R}_{o}$ values of Chang-7 shales ranges from $0.848 \%$ to $0.976 \%$, while $\mathrm{R}_{o}$ of Chang-9 shale varies from $0.93 \%$ to $1.094 \%$, indicating that both the Chang-7 and Chang-9 member are in the mature stage, and shale gas and residual oil may coexist in the shale pores (Table 1, Figure 2c). 


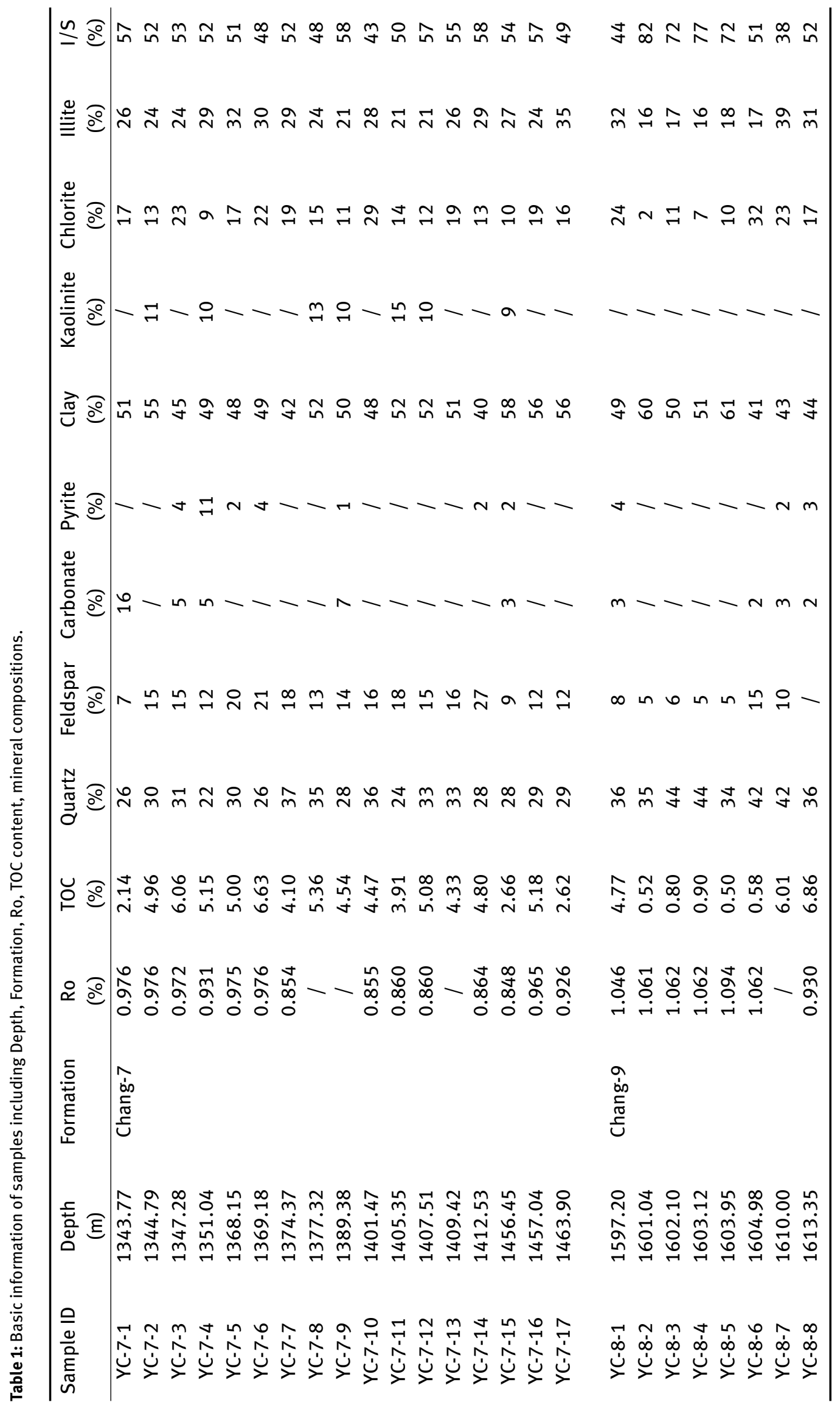



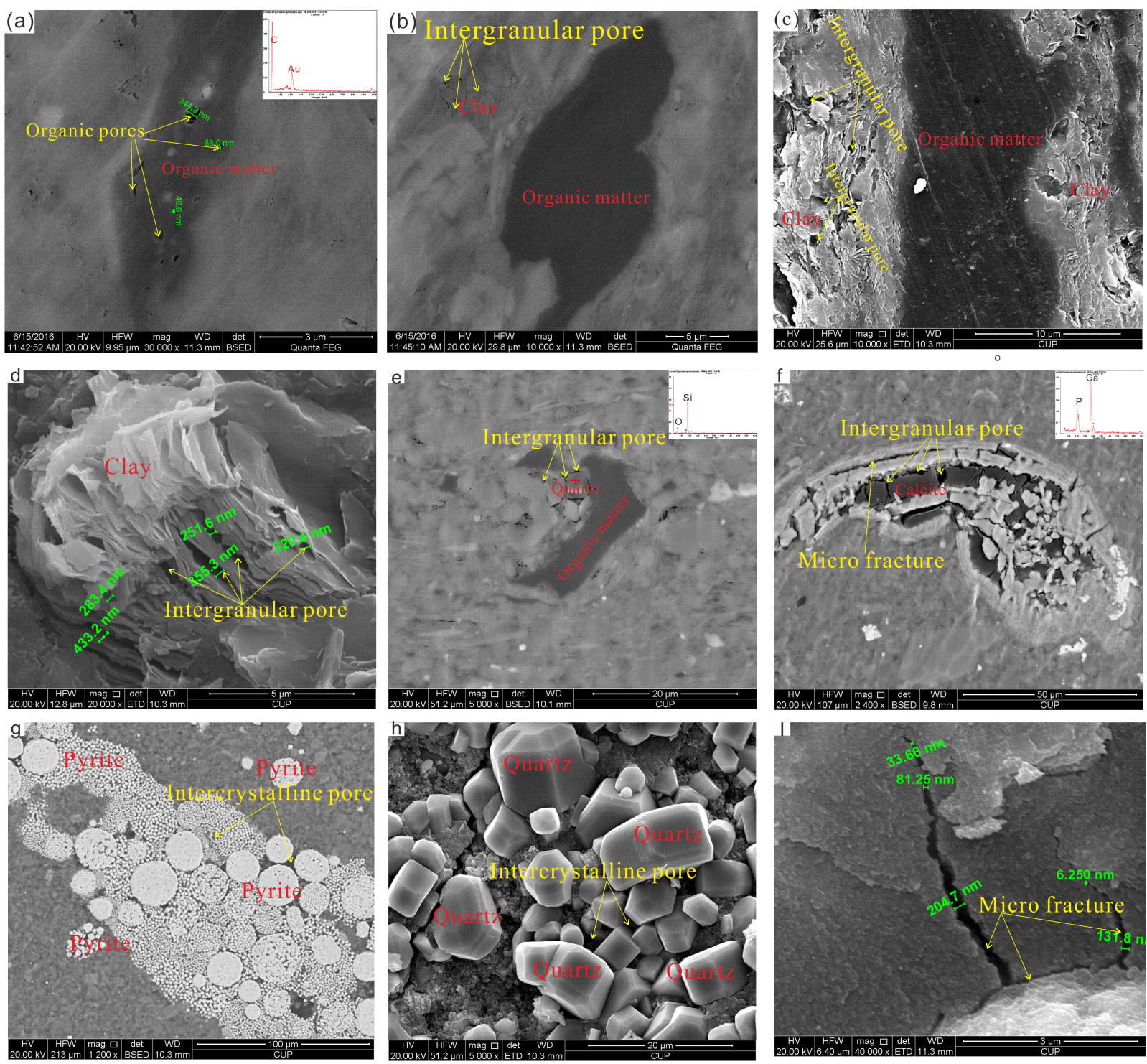

Figure 3: FE-SEM images of the lacustrine shale samples in Ordos Basin. (a) Organic matter with less pores; (b-c) Intergranular pores between organic matter and clay minerals; (d) Intergranular pores in the clay minerals; (e) Intergranular pores between quartz grains and organic matter; (f) Intergranular pores and micro fracture in the calcites; (g-h) Intercrystallite pores in the pyrite and quartz grains; (i) Microfractures in the mineral grains.

\subsection{Pore structure characteristics}

\subsubsection{FE-SEM imaging}

Following the classification of Loucks et al. (2012), organic matter (OM) pores, intergranular pores and microfractures were observed in FE-SEM images (Figure 3). The width of typical pores displays a wide range of $6.25-433.2 \mathrm{~nm}$, indicating heterogeneous pore systems in the lacustrine shale samples. OM pores show heterogeneous distribution with abundant organic matter grains have very few isolated $\mathrm{OM}$ pores (Figure 3a-c). The intergranular pores are the dominate types in the selected lacustrine shales. Such pores are primarily hosted in the framework of clay interlayers, quartz grains and pyrite framboids (Figure $3 \mathrm{~d}-\mathrm{g}$ ). Intercrystallite pores are identified within pyrite framboids and quartz grains (Figure 3g, 3h). A few microfractures, with widths of 33-200 $\mathrm{nm}$ and lengths of $5 \mu \mathrm{m}$, were also observed along grain rims (Figure 3i). 


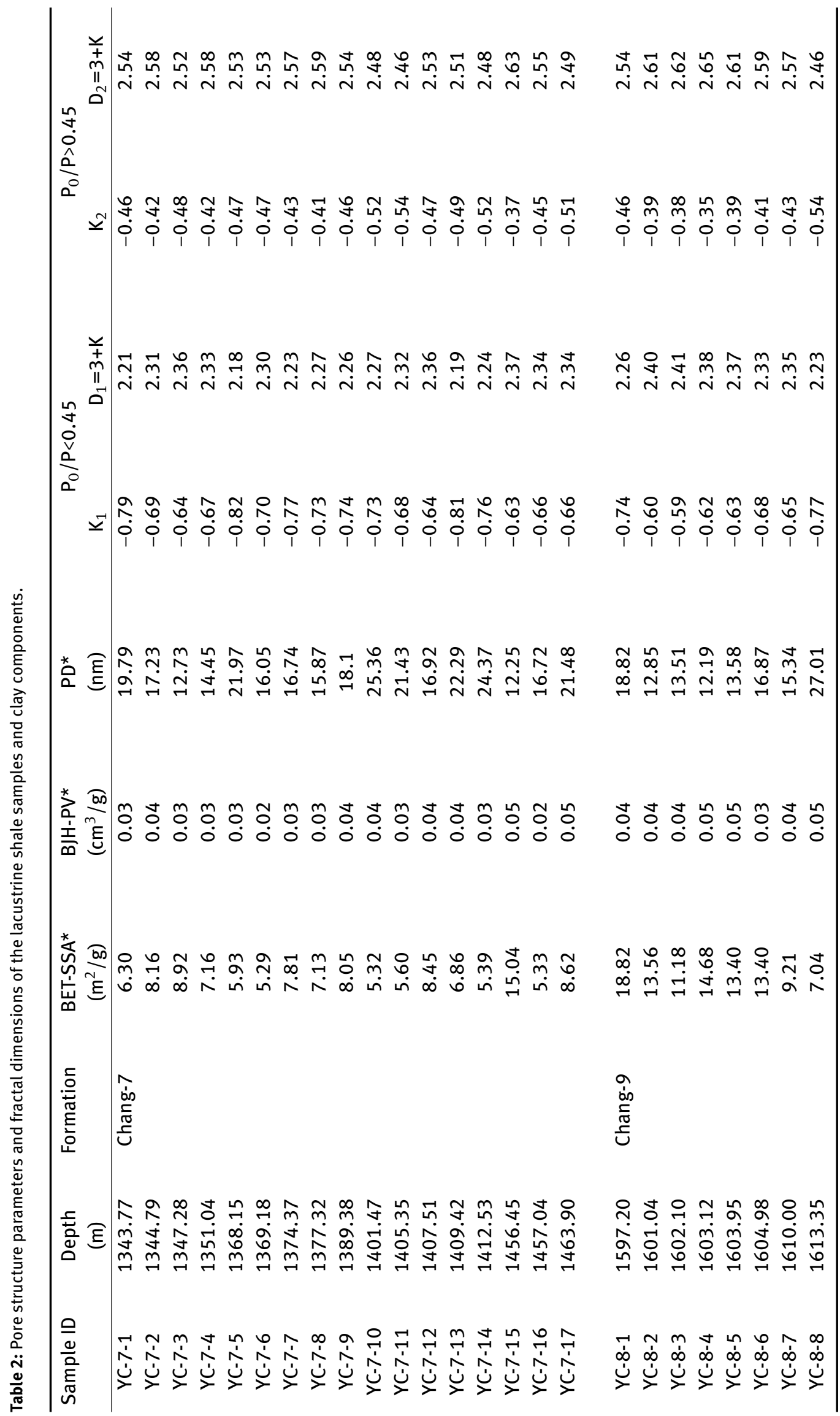



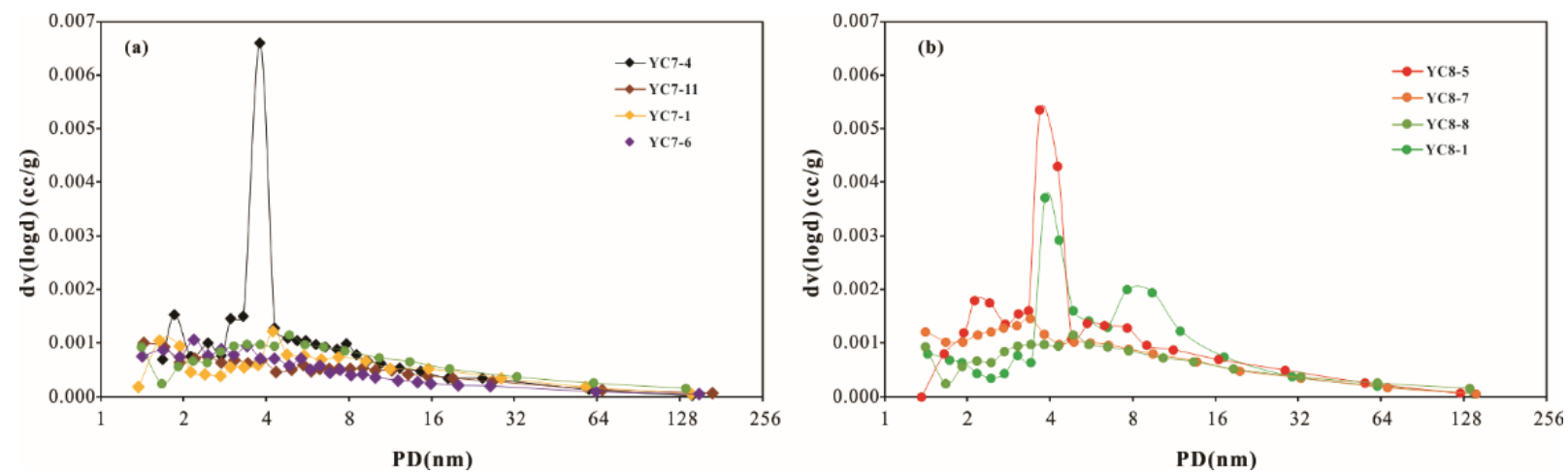

Figure 4: Pore diameter distribution of (a) Chang-7 and (b) Chang-9 shales in Ordos Basin.
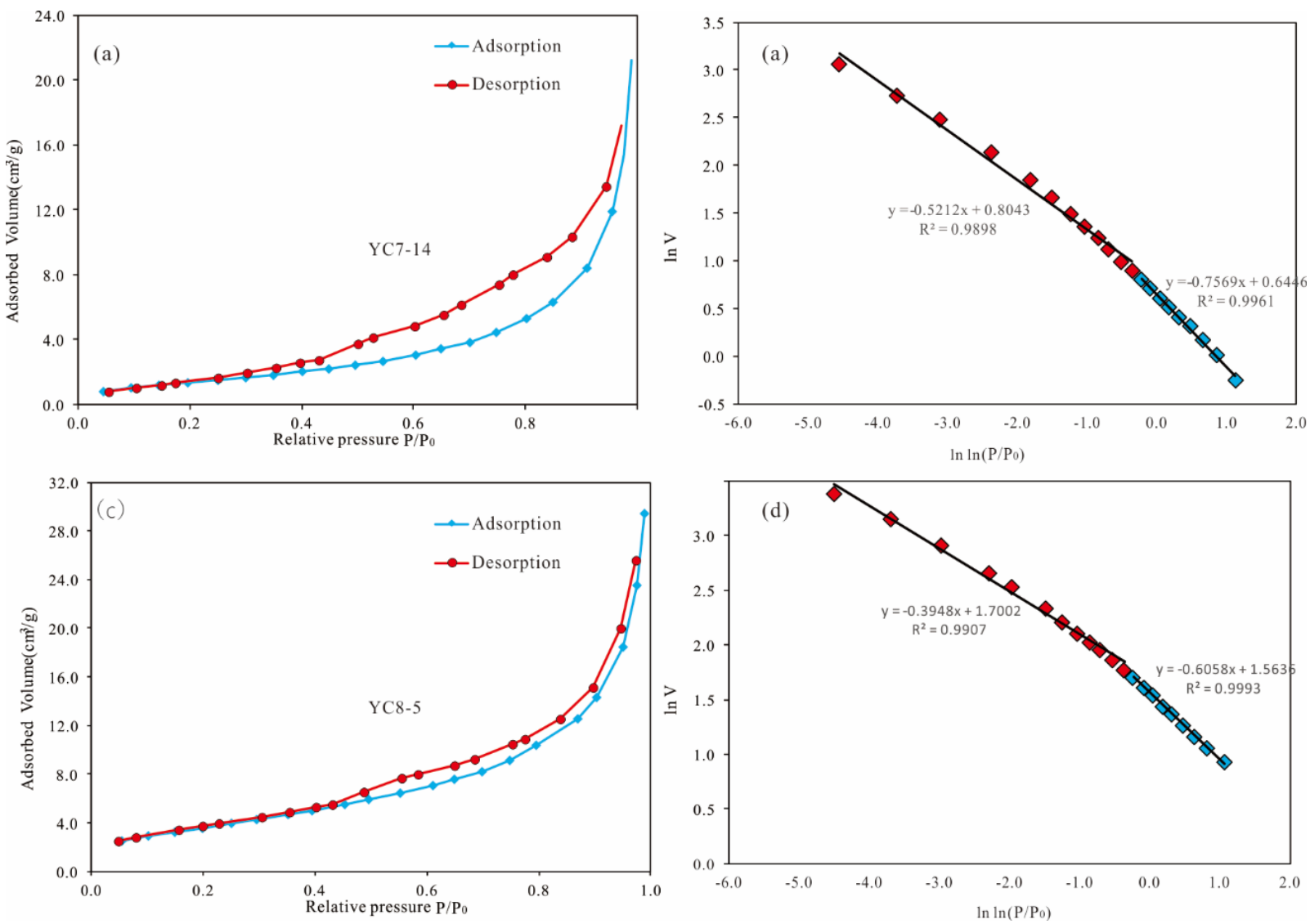

Figure 5: LPNP isotherms and $\ln (\mathrm{V})$ vs $\ln \left(\ln \left(\mathrm{P} / \mathrm{P}_{o}\right)\right)$ plots of the Chang-7 and Chang-9 shales in Ordos Basin. (a)-(b) Chang-7 shales; (c)-(d) Chang-9 shales.

\subsubsection{Pore structure parameters obtained from LPNP data}

Pore structure parameters, including BET specific surface area (SSA), BJH pore volume (PV) and average pore diameter (PD), were listed in Table 2. SSAs of the Chang-7 shales are slightly lower than that of the Chang-9 shales, with average SSAs of $7.37 \mathrm{~m}^{2} / \mathrm{g}$ and $12.66 \mathrm{~m}^{2} / \mathrm{g}$ of Chang-7 shales and Chang-9 shales, respectively. PVs of Chang-9 member are greater than that of Chang-7 member. The PVs in Chang7 shales vary from $0.022 \mathrm{~cm}^{3} / \mathrm{g}$ to $0.047 \mathrm{~cm}^{3} / \mathrm{g}$, while the PVs in Chang-9 shales range from $0.026 \mathrm{~cm}^{3} / \mathrm{g}$ to 0.049 $\mathrm{cm}^{3} / \mathrm{g}$. The average pore width (PD) of the Chang-7 member is bigger than that of the Chang-9 member (Table 2). The plot of $\mathrm{dV} / \mathrm{d}(\log \mathrm{d})$ versus pore size is shown in Figure 4 to illustrate the pore size distribution of the selected lacustrine shales in this paper. Bimodal features are observed, indicating the shales are dominated by mesopores with differ- 

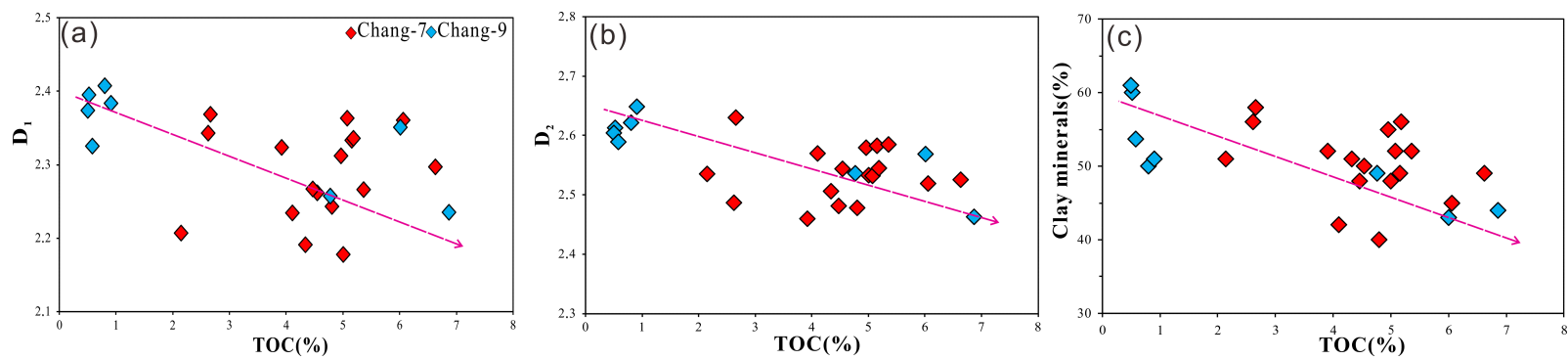

Figure 6: Relationship between fractal dimensions $\left(D_{1}, D_{2}\right)$ and TOC content.

ent pore width. Pore size distributions of the Chang-7 and Chang-9 shales are in the range of 2-16 $\mathrm{nm}$ (mesopores).

\subsection{Fractal dimensions}

Two linear segments occur in the $\ln (\mathrm{V})-\ln \left(\ln \left(\mathrm{P}_{0} / \mathrm{P}\right)\right)$ plots at relative pressures of $0-0.45$ and $0.45-1$ (Figure 5), indicating different nitrogen adsorption mechanisms [10, 14]. The fractal dimension $\mathrm{D}_{1}$ at a lower relative pressure of 0-0.45 represents the effects of Van der Waals forces and indicates the surface fractal dimension. While, the fractal dimension $\mathrm{D}_{2}$ at a higher relative pressure of $0.45-1$ corresponds to the results of capillary condensation and represents the pore structure fractal dimension [14].

The fitting equations, correlation coefficients and fractal dimensions are listed in Table 2. For the Chang-7 shales, the $D_{1}$ values are ranging from 2.17 to 2.36 and the $D_{2}$ values are ranging from 2.63 to 2.46 . For Chang-9 shales, the $D_{1}$ values are in the range of 2.40 to 2.23 and the $D_{2}$ values are in the range of 2.64 to 2.46 . The generally larger $D_{2}$ values indicate that larger pores in the selected samples have more heterogeneous pore volumes compared with pores of smaller width. These results indicate that the lacustrine shales in the present study have complex pore structure.

\section{Discussion}

\subsection{Relationships between fractal dimensions and shale compositions}

As shown in Figure 6, fractal dimensions $\mathrm{D}_{1}$ and $\mathrm{D}_{2}$ have negative correlations with TOC content of the lacustrine shales in this work. This result is inconsistent with the fractal dimensions of the over-mature marine shales [10, 17, 18]. Shales may contain OM pores due to thermal maturation $[3,4,24,25]$, and OM pores with smaller pore width may result in more complex pore networks, consequently, increasing the fractal dimensions $\mathrm{D}_{1}$ and $\mathrm{D}_{2}$. In FE-SEM images, very few $\mathrm{OM}$ pores were observed and inorganic pores especially intergranular pores, intercrystalline pores and micro fracture are mostly developed in the selected lacustrine shales (Figure 3), which may explain the opposite correlations of fractal dimensions with TOC content.

Figure 7 presented the relationships between fractal dimensions $\left(D_{1}, D_{2}\right)$ and bulk mineral compositions including clay minerals, quartz, feldspar and I/S. With the increase of clays and I/S, both $D_{1}$ and $D_{2}$ increase. Clay minerals are the main constituent in lacustrine shales with an average content of 50\% (Table 1). In addition, illite/smectite (I/S) is the main component in the clay minerals. As the clay minerals host abundant complicated inorganic pores, enhancing the heterogeneity of pore structures. In the Figures 7e-f, the relationship between fractal dimensions and quartz content displays slightly positive correlations. This is because the development of few intergranular pores and fractures are associated with quartz detrital (Figure 3), and the irregular shaped may result in more complex pore system and increasing in fractal dimensions [10].

\subsection{Relationships between fractal dimensions and pore structure parameters}

To reveal the impacts of pore structure on fractal dimensions of lacustrine shales, correlations of fractal dimensions with pore volume and average pore diameter were discussed. Both $D_{1}$ and $D_{2}$ have undefined correlations with PV (Figure 8a, b), suggesting pore volume has little effect on fractal dimensions. It may be because complex pore systems have larger pore volumes, resulting in more complicated fractal dimensions $[8,17,26]$. The difference between $\mathrm{D}_{1}$ and $\mathrm{D}_{2}$ indicate that pore volume has some different influences on fractal dimensions $\mathrm{D}_{1}$ and $\mathrm{D}_{2}$. 

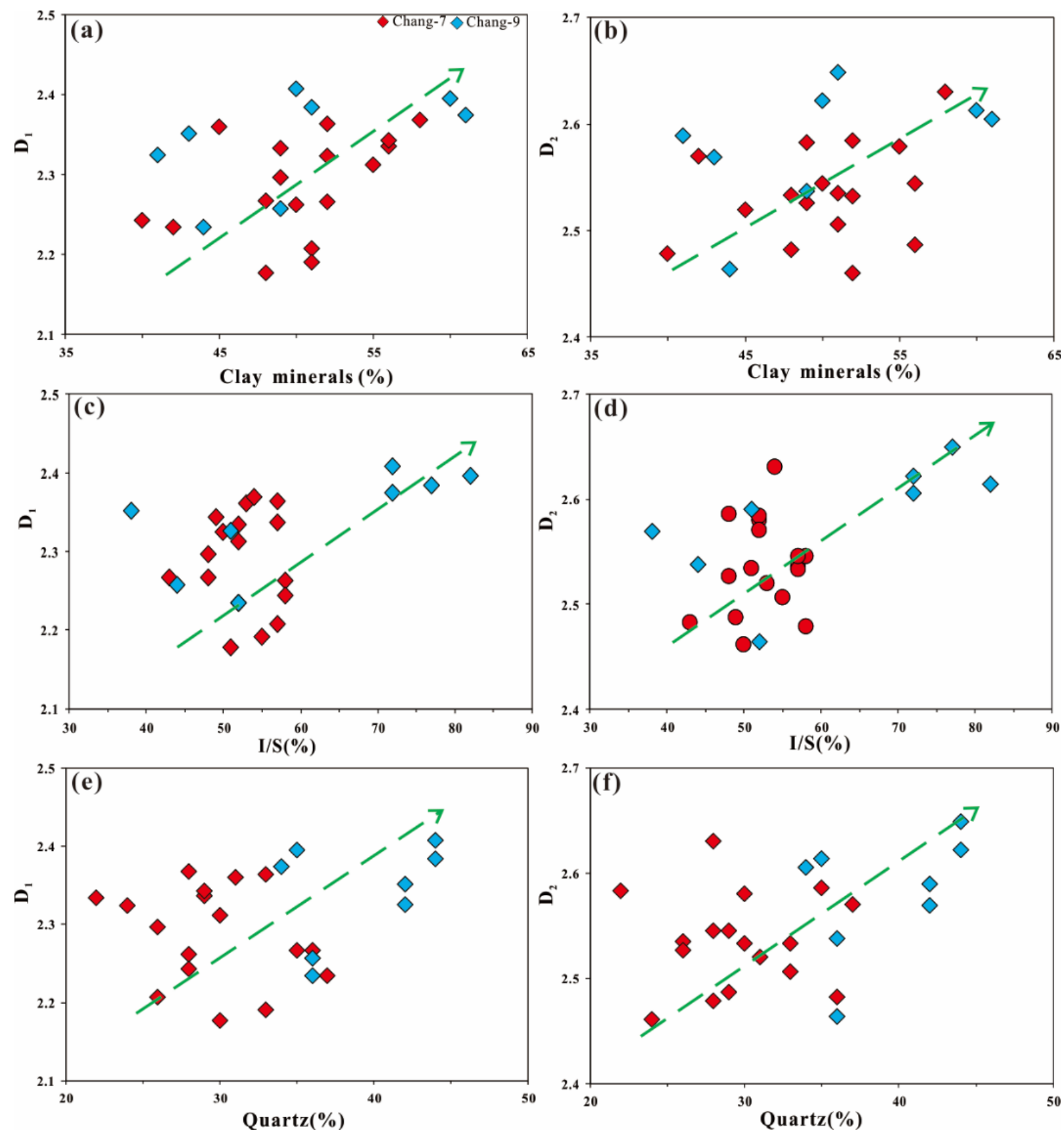

Figure 7: Relationships between fractal dimensions and pore structure parameters.

Both fractal dimensions $\mathrm{D}_{1}$ and $\mathrm{D}_{2}$ increase with decreasing average pore diameters (Figure 8). Additionally, the correlation of $\mathrm{D}_{2}$ with the average pore diameter is better than that of $D_{1}$ with the average pore diameter, indicating that $D_{2}$ may best represent the pore structure fractal dimension and thus, it is more sensitive to the average pore diameter than $D_{1}$. These findings are consistent with the findings of coal [14], marine gas shale [18] and lacustrine shale [26], which indicating the micropores and mesopores are more complicated than macropores, proba- bly because the small pore diameters have lager fractal dimensions. Shale samples with smaller average pore diameters may also contain more throats and micropores $[8,14]$, which lead to more heterogonous and complicated pore structure and higher fractal dimension $\mathrm{D}_{2}$ values. 

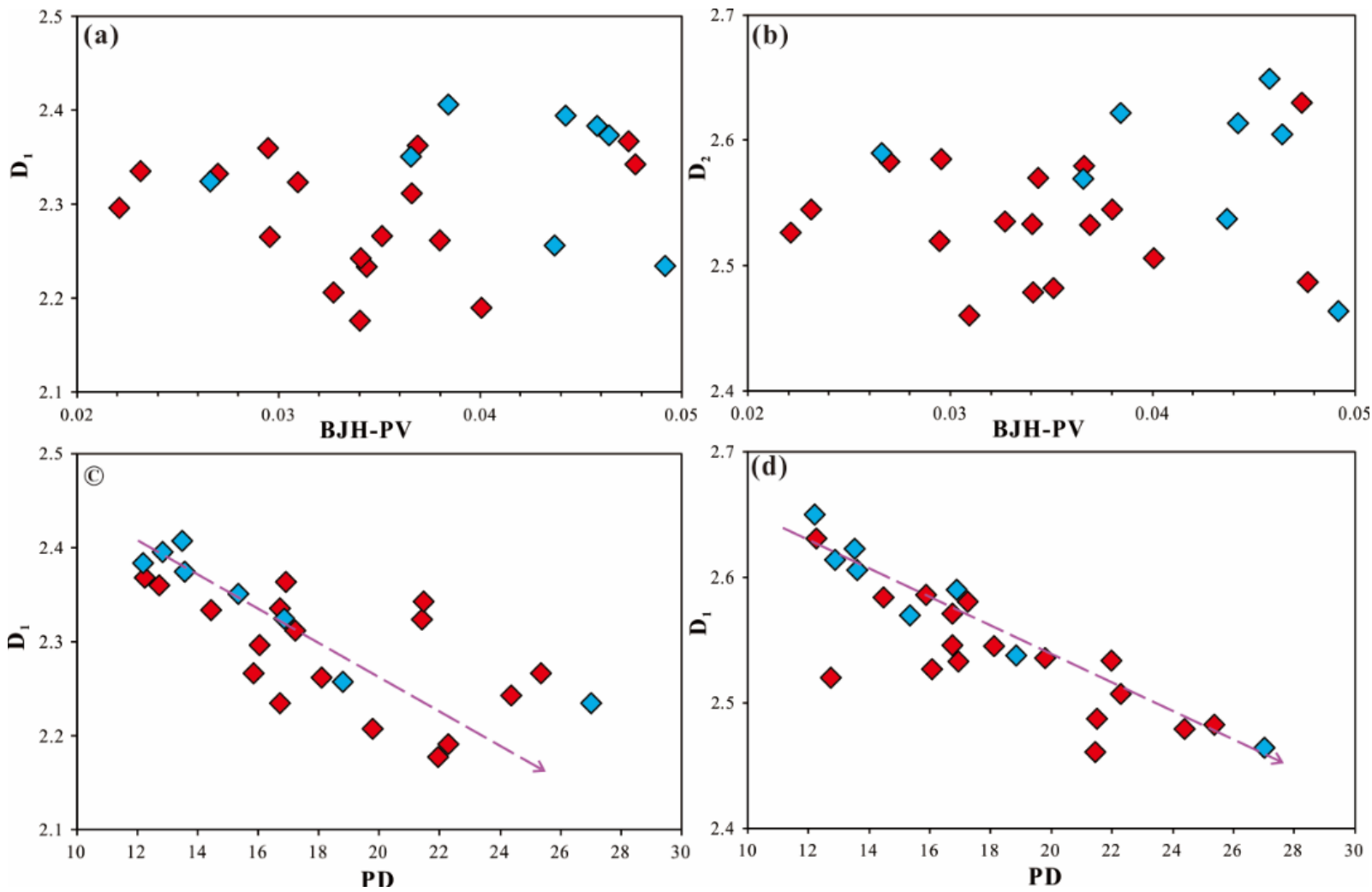

Figure 8: Relationship between fractal dimensions $\left(D_{1}, D_{2}\right)$ and pore structure parameter.
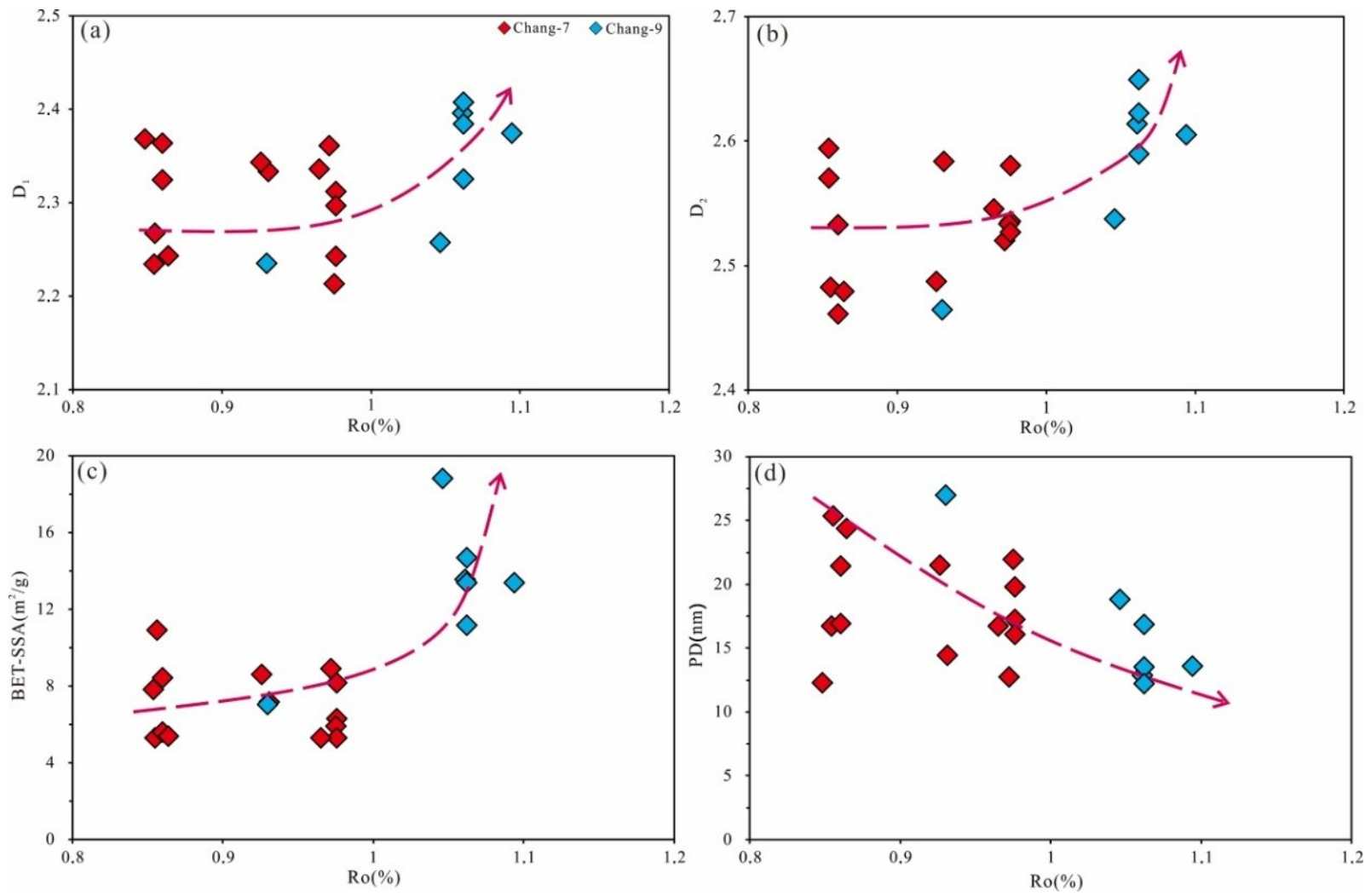

Figure 9: Relationship between fractal dimensions $\left(D_{1}, D_{2}\right)$ and Ro. 


\subsection{Comparison of fractal characteristics between Chang-7 and Chang-9 shales}

Both fractal dimensions $\mathrm{D}_{1}$ and $\mathrm{D}_{2}$ in Chang-9 shales are higher than those in Chang-7 shales (Figure 9, Table 2), suggesting more irregular and nonhomogeneous pores in Chang-9 shales. The maturity of Chang- 9 shale is generally larger than that of Chang-7 shale due to the burial depth, resulting in the fractal dimensions $\left(\mathrm{D}_{1}\right.$ and $\left.\mathrm{D}_{2}\right)$ of the Chang9 shale being higher than that of Chang-7 shale (Figure 9, Table 2). With the increase of burial depth and thermal maturity, the generation of more hydrocarbons break brittle minerals to form micro fractures which make pores more irregular. In addition, more smectite converted into I/S mixed layer, leading to a higher SSA and PV [10, 26]. In addition, the fractal dimensions keep steady,maybe because the generated oil occupying the macro-nanopores is balancing the generated organic pores [26, 27]. For pore structure parameters of the Yanchang shale samples, SSA of Chang-7 member is lower than that of in the Chang-9 member. Chang-9 member has a much larger PV than that in the Chang-7 member. For the average PD, the Chang-7 shale is bigger than that of the Chang-9 shale. Further study should be focused on the difference in shale reservoir characteristics, especially pore structure features between two target layers Chang-7 member and Chang-9 member, which has not been further quantitatively revealed and compared.

\section{Conclusions}

Based on our study, the following conclusions can be drawn.

(1) Two fractal dimensions, $\mathrm{D}_{1}$ and $\mathrm{D}_{2}$, were obtained at relative pressures of 0-0.45 and 0.45-1 using the $\mathrm{FHH}$ method. The Chang-7 shales have $\mathrm{D}_{1}$ and $\mathrm{D}_{2}$ range of 2.17-2.36 and 2.46-2.63, while the Chang-9 shales have $D_{1}$ values of 2.23-2.40 and $D_{2}$ values of 2.46-2.64. The fractal dimensions $\left(D_{1}, D_{2}\right)$ of Chang-7 shale are generally lower than that of Cheng-9 shale, which results in Chang 9 shale developing more complex pore structure due to its higher maturity.

(2) Fractal dimensions of the selected lacustrine shales are affected by shale mineral compositions and pore structure parameters. Positive correlations of $\mathrm{D}_{1}$ and $\mathrm{D}_{2}$ with Clay minerals and quartz contents and negative correlations of $D_{1}$ and $D_{2}$ with TOC contents were presented in the present study. Observations of a few organic matter pores and abundant inorganic pores hosted in the Yanchang shales may contribute to these correlations.

(3) Comparisons of matrix composition and pore characteristics between the Chang-7 shales and the Chang-9 shales suggest the latter may have a more irregular and heterogeneous pore structure.

Acknowledgement: This study was supported by the by the National Natural Science Foundation of China (No. 19641502123 and No. U1562215) and the National Major Project of China (No. 2017ZX05035-197 002 and No. 201605034-001).

\section{References}

[1] Curtis M.E., Cardott B.J., Sondergeld C.H., Rai C.S., Development of organic porosity in the Woodford Shale with increasing thermal maturity. International Journal of Coal Geology., 2012, 103(23), 26-31

[2] Jarvie D.M., Hill R.J., Ruble T.E., Pollastro R.M., Unconventional shale-gas systems: the Mississippian Barnett Shale of northcentral Texas as one model for thermogenic shale-gas assessment. AAPG Bull., 2007, 91, 475-499

[3] Ross D.J.K., Bustin R.M., The importance of shale composition and pore structure upon gas storage potential of shale gas reservoirs. Marine and Petroleum Geology., 2009, 26(6), 0-927

[4] Loucks R.G., Reed R.M., Ruppel S.C., Hammes U., Spectrum of pore types and networks in mudrocks and a descriptive classification for matrix-related mudrock pores[]]. AAPG bulletin., 2012, 96(6), 1071-1098.

[5] Clarkson C.R., Solano N., Bustin R.M., Bustin A.M.M., Chalmers G.R.L., He L., Melnichenko Y.B., Radliński A.P., Blacn T.P., Pore structure characterization of North American shale gas reservoirs using USANS/SANS, gas adsorption, and mercury intrusion. Fuel., 2013, 103(1), 606-616

[6] Wang J., Liu H.Q., Wang L., Zhang H.L., Luo H.S., Gao Yang., Apparent permeability for gas transport in nanopores of organic shale reservoirs including multiple effects[]]. International Journal of Coal Geology., 2015, 152, 50-62.

[7] Mastalerz M., Schimmelmann A., Drobniak A., Chen Y.Y., Porosity of Devonian and Mississippian New Albany Shale across a maturation gradient: Insights from organic petrology, gas adsorption, and mercury intrusion. AAPG Bulletin., 2013, 97(10), 1621-1643

[8] Yang F., Ning Z.F., Wang Q., Kong D.T., Xiao L.F., Fractal Characteristics of Nanopore in Shales. Natural Gas Geoscience., 2014, 25(4), 618-623

[9] Tang X.L., Jiang Z.X., Jiang S., Li Z., Heterogeneous nanoporosity of the Silurian Longmaxi Formation shale gas reservoir in the Sichuan Basin using the QEMSCAN, FIB-SEM, and nano-CT methods. Marine and Petroleum Geology., 2016, 78, 99-109.

[10] Shao X.H., Pang X.Q., Li Q.W., Wang P.W., Chen D., Shen W.B., Zhao Z.F., Pore structure and fractal characteristics of organicrich shales: A case study of the lower Silurian Longmaxi shales in the Sichuan Basin, SW China. Marine and Petroleum Geology., 2017, 80, 192-202 
[11] Kong L., Ostadhassan M., Li C.X., Tamimi N., Pore characterization of 3D-printed gypsum rocks: a comprehensive approach. Journal of Materials Science., 2018, 53(7), 5063-5078

[12] Pfeifer P., Avnir D., Chemistry in noninteger dimensions between two and three. I. Fractal theory of heterogeneous surfaces. Journal of Chemical Physics., 1983, 79(7), 3558-3565

[13] Ding Y., Weller A., Zhang Z.Y., Kassab M., Halisch M., Fractal dimension of pore space in carbonate samples from Tushka area (Egypt). Arabian Journal of Geosciences., 2017, 10(17), 388

[14] Yao Y.B., Liu D.M., Tang D.Z., Tang S.H., Huang W.H., Fractal characterization of adsorption-pores of coals from North China: an investigation on $\mathrm{CH} 4$ adsorption capacity of coals. International Journal of Coal Geology., 2008, 73 (1), 27-42

[15] Liu X., Xiong J., Liang L., Investigation of pore structure and fractal characteristics of organic-rich Yanchang formation shale in central China by nitrogen adsorption/desorption analysis. Plateau Meteorology., 2015, 22(7), 62-72

[16] Tang X.L., Jiang Z.X., Li Z., Gao Z.Y., Bai Y.Q., Zhao S., Feng J., The effect of the variation in material composition on the heterogeneous pore structure of high-maturity shale of the Silurian Longmaxi formation in the southeastern Sichuan Basin, China. Journal of Natural Gas Science and Engineering., 2015, 23, 464473

[17] Ji W.M., Song Y., Jiang Z.X., Meng M.M., Liu Q.X., Chen L., Fractal characteristics of nano-pores in the lower silurian longmaxi shales from the upper yangtze platform, south china. Marine and Petroleum Geology., 2016, 78, 88-98

[18] Yang F., Ning Z., Liu H.Q., Fractal characteristics of shales from a shale gas reservoir in the Sichuan Basin, China. Fuel., 2014, 115, 378-384

[19] Liang L., Xiong J., Liu X.J., Fractal characteristics of pore structure of Longmaxi Formation shale in south of Sichuan Basin, China. Journal of Chengdu University of Technology: Science and Technology Edition., 2015, 42(6), 700-707
[20] Gao X., Hu Q., Gao Z., Ewing, R.P. Pore Accessibility and Connectivity of Mineral and Kerogen Phases for Shales. Unconventional Resources Technology Conference., 2016, 2879

[21] Wang L., Fu Y., Li J., Sima L.Q., Wu Q.Z., Jin W.J., Wang T., Mineral and pore structure characteristics of gas shale in Longmaxi formation: a case study of Jiaoshiba gas field in the southern Sichuan Basin, China. Arabian Journal of Geosciences., 2016, 9(19), 733

[22] Zhao H., Dang B., Li W.H., Yang X.Q., Dang Y.Q., Microfacies characteristic of Yanchang Formation in Ansai district. Natural Gas Geoscience., 2004, 15(5), 492-497

[23] Li S.H., Wang G.C., Zhang C.M., Zhang S.F., Peng Y.L., Chen X.M., Yao F.Y., Methods for establishing reservoir geological model-by taking chang 6 section of yanchang formation in pingbei oilfield for example. Journal of Jianghan Petroleum Institute., 2004

[24] Tian H., Pan L., Xiao X.M., Wilkins R.W.T., Meng Z.P., Huang B.J., A preliminary study on the pore characterization of lower silurian black shales in the chuandong thrust fold belt, southwestern china using low pressure $\mathrm{N} 2$ adsorption and fe-sem methods. Marine and Petroleum Geology., 2013, 48, 8-19

[25] Ji W.M., Song Y., Jiang Z.X., Chen L., Li Z., Yang X., Meng M.M., Estimation of marine shale methane adsorption capacity based on experimental investigations of lower silurian longmaxi formation in the upper yangtze platform, south china. Marine and Petroleum Geology., 2015, 68, 94-106

[26] Jiang F., Chen D., Chen J., Li Q.W., Liu Y., Shao X.H., Hu T., Dai J.X., Fractal analysis of shale pore structure of lacustrine shale gas reservoir in the Ordos Basin, NW China. Energy and Fuels., 2016, 30(6)

[27] Yao Y.B., Liu D.M., Tang D.Z., Tang S.H., Huang W.H., Liu Z.H., Che Y., Fractal characterization of seepage-pores of coals from China: an investigation on permeability of coals. Computers and Geosciences, 2009, 35(6): 1159-1166. 